Check for updates

Cite this: Chem. Commun., 2021, 57,12337

Received 25th August 2021,

Accepted 20th September 2021

DOI: $10.1039 / \mathrm{d} 1 \mathrm{cc} 04737 \mathrm{j}$

rsc.li/chemcomm

\section{C-H Electrophilic (phenylsulfonyl)difluoromethylation of (hetero)arenes with a newly designed reagent $\dagger$}

\author{
Enzo Nobile, (D) Thomas Castanheiro (D) and Tatiana Besset (D) *
}

\begin{abstract}
The synthesis of an original electrophilic difluoromethylating reagent was successfully achieved upon a straightforward protocol (3 steps). Like a Swiss army knife, this bench-stable reagent allowed the functionalization of various classes of compounds under mild and transition metalfree conditions. Hence, an efficient and operationally simple tool for the construction of $\mathrm{C}\left(\mathrm{sp}^{2}\right)-, \mathrm{C}\left(\mathrm{sp}^{3}\right)-$ and $\mathrm{S}-\mathrm{CF}_{2} \mathrm{SO}_{2} \mathrm{Ph}$ bonds was provided, expanding the chemical space of $\mathrm{PhSO}_{2} \mathrm{CF}_{2}$-containing molecules. Latestage functionalization of bioactive molecules and the synthesis of $\mathrm{PhSO}_{2} \mathrm{CF}_{2^{-}}$and $\mathrm{HCF}_{2}$-analogs of Lidocaine were also successfully achieved.
\end{abstract}

Organofluorine chemistry is a research area of paramount importance as fluorinated molecules are prevalent derivatives in materials science, and the agrochemical and pharmaceutical industries. ${ }^{1}$ More than $40 \%$ of pharmaceuticals approved by the FDA in 2019 contain at least one fluorine atom, ${ }^{2}$ which can be explained by the fact that the incorporation of a fluorine atom or a fluorinated moiety drastically impacts the properties of the corresponding molecules. ${ }^{3}$ Therefore, over the years, the field of organofluorine chemistry has been revolutionized by impressive advances including original and efficient transformations along with the discovery and design of potent fluorinated groups, which have widened the chemical space of fluorinated compounds. ${ }^{4}$ Whilst special attention was paid to the $\mathrm{HCF}_{2}$ group, ${ }^{5}$ design of the $\mathrm{FGCF}_{2}$ moiety has emerged as an interesting lead to be followed. Among them, the $\mathrm{PhSO}_{2} \mathrm{CF}_{2}$ residue proved to be of high importance and has aroused the interest of the scientific community. ${ }^{6}$ Found in the analog of Fluconazole with antifungal activities, ${ }^{7}$ this fluorinated group is a real synthetic handle. Indeed, it is easily converted into other valuable difluorinated moieties such as the difluoromethyl $\left(\mathrm{HCF}_{2}\right)$, the difluoromethylene $\left(-\mathrm{CF}_{2}-\right)$, and the difluoromethylidene $\left(=\mathrm{CF}_{2}\right)$

Normandie Univ, INSA Rouen, UNIROUEN, CNRS, COBRA (UMR 6014),

76000 Rouen, France.E-mail: tatiana.besset@insa-rouen.fr

$\dagger$ Electronic supplementary information (ESI) available. CCDC 2084628 and 2084629. For ESI and crystallographic data in CIF or other electronic format see DOI: $10.1039 / \mathrm{d} 1 \mathrm{cc} 04737 \mathrm{j}$ groups. These were found in drugs such as Eflornithine ${ }^{8}$ and Seletracetam, ${ }^{9}$ for instance. The main synthetic pathways to build up a C- $\mathrm{CF}_{2} \mathrm{SO}_{2} \mathrm{Ph}$ bond relied on the use of nucleophilic sources of the (phenylsulfonyl)difluoromethyl residue or proceeded via a radical process. ${ }^{6}$ In sharp contrast, methodologies involving electrophilic reagents are restricted to two major contributions from key players in the field, namely the groups of $\mathrm{Hu}^{10}$ and Shibata. ${ }^{11}$ They designed two electrophilic sources based on a hypervalent iodine and a sulfonium salt, respectively (Scheme 1). While the group of Hu showcased that its source was very efficient for the functionalization of thiols as well as for the copper-catalyzed allylic and vinylic (phenylsulfonyl)difluoro-methylation reaction, Shibata and co-workers successfully applied their reagent to the functionalization of $\mathrm{C}\left(\mathrm{sp}^{3}\right)$ centers with $\beta$-ketoesters, $\beta$-diketones and dicyanoalkylidenes. Although those reagents served as a proof-ofconcept, we wondered whether it would be possible to synthesize a new electrophilic reagent, which will (1) be easily accessible on a large scale, (2) not require ozone depleting reagents for its synthesis

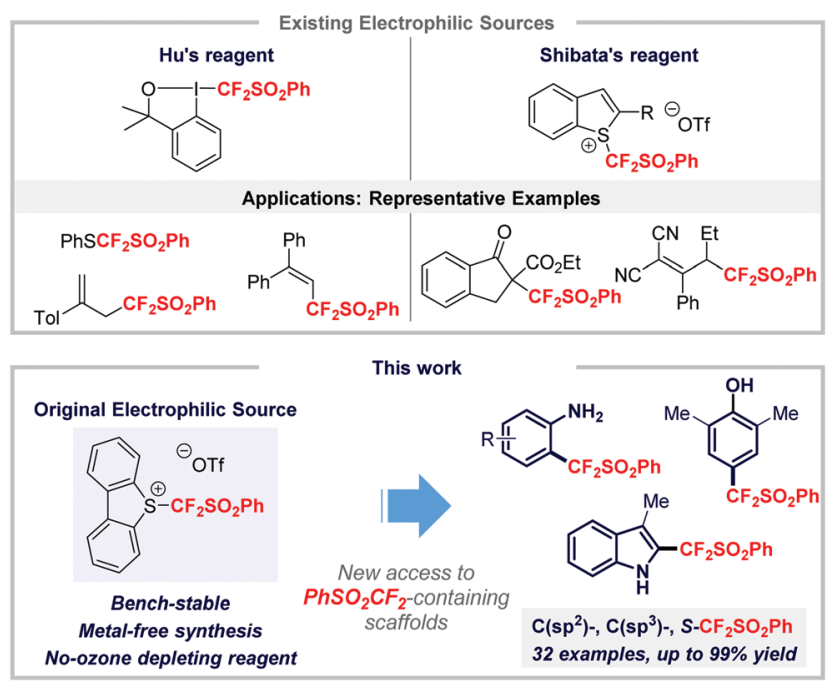

Scheme 1 State of the art and this work. 
and (3) react with a large panel of nucleophiles. Such a reagent will definitely facilitate access to difluoromethylated compounds.

By analogy with Umemoto's reagent and its analogs, ${ }^{12}$ we anticipated that the backbone of the reagent will be important in reaching a good reactivity. Therefore, we envisaged the synthesis of an $S$-([phenylsulfonyl]difluoromethyl)dibenzothiophenium salt. Herein, we disclose a simple and straightforward synthesis of an electrophilic source of a $\mathrm{PhSO}_{2} \mathrm{CF}_{2}$ group and its broad application in various transformations.

With these considerations in mind, we embarked on the preparation of reagent I. This newly designed reagent was synthesized in a three step/one purification sequence in 51\% overall yield starting from the commercially available or easy-to-synthesize biaryl disulfide $1 \mathrm{a}^{13}$ and (difluoromethyl)sulfonylbenzene. ${ }^{14,15}$ First, the (phenylsulfonyl)difluoromethylation of the disulfide 1a under basic conditions provided $\mathbf{1 b}$ in $74 \%$ yield. Selective oxidation of the sulfane with $m$ CPBA furnished 1c in 90\% yield, without any purification. Finally, upon treatment with triflic anhydride, the sulfoxide 1c was converted into the corresponding dibenzothiophenium salt I in $76 \%$ yield. The structure of I was further ascertained using X-ray analysis. ${ }^{15}$ The reagent turned out to be air- and moisture-tolerant and bench-stable and was kept for more than three months at room temperature under air with no alteration of its reactivity. Remarkably, its transition metal-free synthesis did not require any ozone depleting fluorinated reagents (Scheme 2) and was conveniently scalable as reagent I was obtained in $46 \%$ overall yield on a $48 \mathrm{mmol}$ scale.

Having this reagent in hand, we first explored its reactivity towards the (phenylsulfonyl)difluoromethylation of aniline derivatives with complete selectivity towards the formation of a $\mathrm{C}\left(\mathrm{sp}^{2}\right)-\mathrm{CF}_{2} \mathrm{SO}_{2} \mathrm{Ph}$ bond (Scheme 3). When aniline 2a was reacted with reagent $\mathbf{I}$, compound $\mathbf{3 a}$ was obtained in a high yield as an easy-to-separate mixture of ortho and para regioisomers, the ortho isomer being the major one. ${ }^{15,16}$ As these fluorinated molecules might be of high interest for medicinal chemistry and drug discovery, access to both regioisomers in one transformation might constitute a substantial advantage. Then, a panel of original and diversely para-substituted (phenylsulfonyl)difluoromethylated anilines was synthesized. Anilines substituted with electron-donating groups (2b-2d),

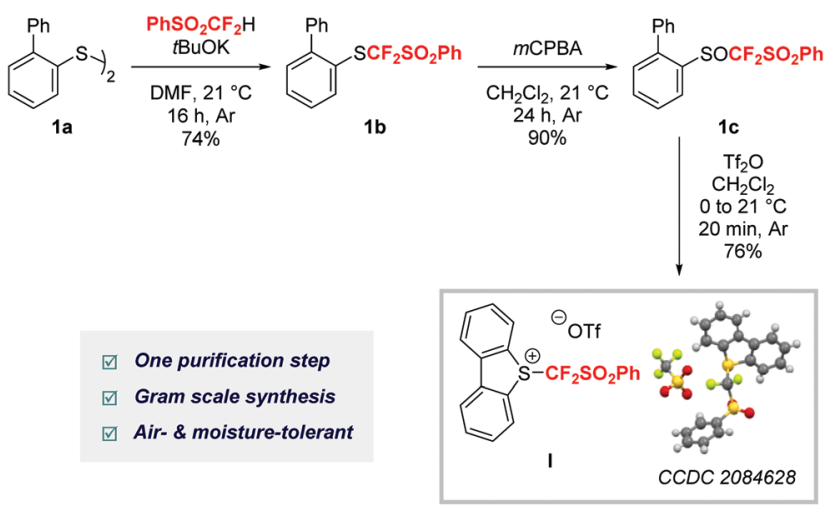

Scheme 2 Synthesis of reagent I. Reaction performed on a $5 \mathrm{mmol}$ scale. See the ESI $\dagger$ for more details.

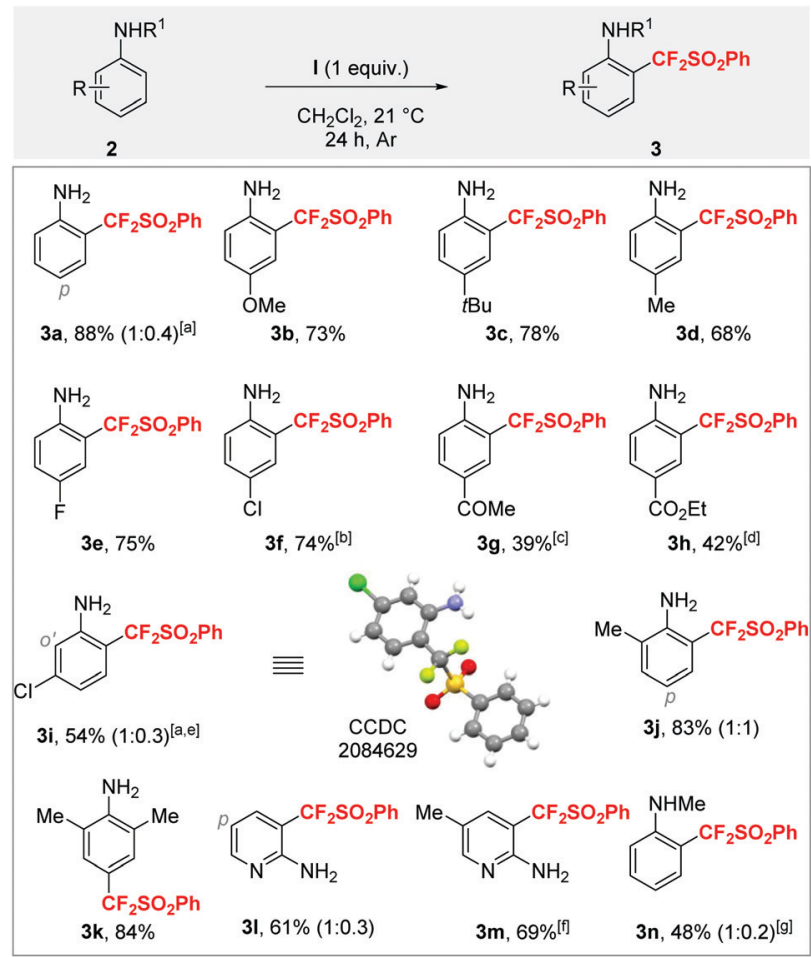

Scheme 3 (Phenylsulfonyl)difluoromethylation of anilines 2 . Reaction conditions: 2 (3 equiv.), I ( $0.3 \mathrm{mmol}, 1$ equiv.), $\mathrm{CH}_{2} \mathrm{Cl}_{2}(0.15 \mathrm{M}), 21^{\circ} \mathrm{C}, 24 \mathrm{~h}$, under argon. Isolated yields are given. In the case of the regioisomers, combined isolated yields were provided and the ratio of regioisomers, in parentheses, was determined using ${ }^{19} \mathrm{~F}$ NMR of the crude reaction mixture using $\alpha, \alpha$, $\alpha$-trifluoro-acetophenone as an internal standard. ${ }^{a}$ The minor isomer was isolated with an inseparable impurity. ${ }^{b} 8$ days. ${ }^{c} 10$ days. ${ }^{d} 12$ days. ${ }^{e} 4$ days. ${ }^{f}$ The product was isolated with an inseparable impurity. ${ }^{9}$ Only this isomer was isolated in $48 \%$ yield.

halogens (2e and $\mathbf{2 f}$ ) and electron-withdrawing groups (2g and 2h) were all suitable substrates, the transformation being more efficient with electron-rich compounds. The reaction was tolerant towards various functional groups such as ketones (3g) and esters $(3 \mathbf{h})$. When the 3 -chloroaniline $2 \mathbf{i}$ reacted with reagent $\mathbf{I}$, the functionalization occurred on both ortho positions, and the major isomer, resulting from the (phenylsulfonyl)difluoromethylation at the less sterically hindered position, was preferentially obtained as ascertained using NMR experiments and X-ray analysis (CCDC 2084629). ${ }^{15}$ In the case of 2-methylaniline, a 1:1 mixture of both the ortho- and parasubstituted products (3j) was obtained in $83 \%$ yield as confirmed using 2D-NMR experiments. Interestingly, the 2 , 6-xylidine $\mathbf{2 k}$, a key scaffold found in several anesthetics such as Lidocaine, Bupicaine, Mepivacaine and Etidocaine, was smoothly functionalized in $84 \%$ yield. It is worth mentioning that heteroarylamines ( $2 \mathbf{l}$ and $\mathbf{2 m}$ ) were also functionalized in good yields. ${ }^{15}$ The methodology was not restricted to the functionalization of primary anilines as $\mathrm{N}$-methylaniline reacted and $3 \mathrm{n}$ was isolated in $48 \%$ yield for the ortho isomer.

Encouraged by these results, we turned our attention to the electrophilic (phenylsulfonyl)difluoromethylation of electronrich (hetero)arenes (Scheme 4). First indoles (4a-4e), a key 


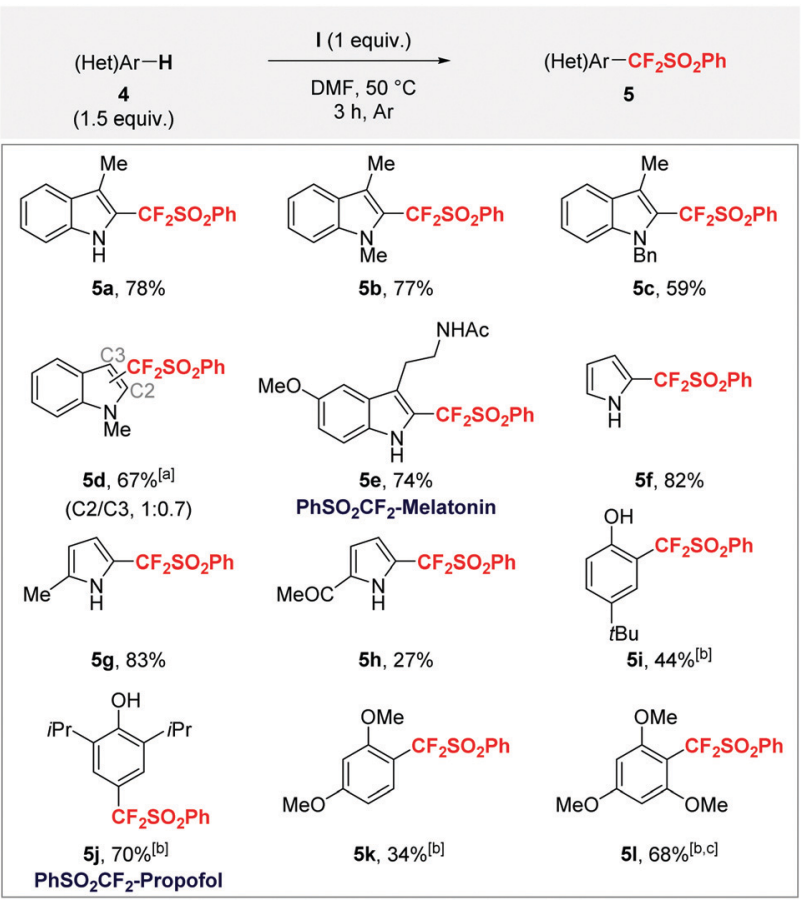

Scheme 4 Electrophilic (phenylsulfonyl)difluoromethylation of electronrich (hetero)arenes. Reaction performed on a $0.3 \mathrm{mmol}$ scale. Isolated yields are given. ${ }^{a} \mathrm{~A}$ combined isolated yield was provided and the ratio of regioisomers was determined using ${ }^{19} \mathrm{~F}$ NMR of the crude reaction mixture using $\alpha, \alpha, \alpha$-trifluoroacetophenone as an internal standard. The C3-regioisomer of $\mathbf{5 d}$ was isolated with traces of the C4-regioisomer. ${ }^{b}$ Reactions performed using 3 equivalents of $\mathbf{4}$ in DMSO, $50{ }^{\circ} \mathrm{C}, 16 \mathrm{~h}$, under argon. ${ }^{\mathrm{C}} \mathbf{5 l}$ was isolated with $13 \%$ of $\mathbf{4 l}$ remaining

scaffold for medicinal chemistry, were studied. Non-protected and $N$-protected 3-substituted indoles $(\mathbf{4 a - 4 c )}$ were smoothly functionalized at the $\mathrm{C} 2$ position. When the $N$-methylindole $4 \mathbf{d}$ was used as the substrate, the expected product $\mathbf{5 d}$ was obtained as a mixture of regioisomers. Interestingly, the C2-functionalization of pyrroles was efficiently achieved, except in the case of $\mathbf{5 h}$, which was isolated in a modest $27 \%$ yield. The (phenylsulfonyl)difluoromethylation of phenol and anisole derivatives (4i-4l) provided the corresponding products in decent to good yields. The late-stage functionalization of bioactive molecules such as Melatonin (4e), "the sleep hormone", and Propofol (4j), a potent anesthetic, went smoothly. The expected products (5e and $\mathbf{5 j}$ ) were obtained with complete regioselectivity in $74 \%$ and $70 \%$ yields, respectively. To further demonstrate the potential of reagent $\mathbf{I}$, the functionalization of $\mathrm{C}\left(\mathrm{sp}^{3}\right)$-centered nucleophiles was studied (Scheme 5). Pleasingly, in the presence of DBU, $\beta$-ketoesters 6 and dicyanoalkylidene $\mathbf{8}$ were efficiently functionalized at low temperature $\left(-78{ }^{\circ} \mathrm{C}\right.$ or $\left.-42{ }^{\circ} \mathrm{C}\right)$ and the corresponding (phenylsulfonyl) difluoromethylated products $7 \mathbf{a}, 7 \mathbf{b}$ and $\mathbf{9}$ were isolated in good to excellent yields with complete selectivity for the C-functionalization: a valuable alternative to the pioneering work from Shibata. ${ }^{11}$ Due to the recent interest in the (phenylsulfonyl)difluoromethyl sulfanyl group, ${ }^{10 a, 17}$ we explored the possibility of accessing $\mathrm{PhSO}_{2} \mathrm{CF}_{2} \mathrm{~S}$-containing derivatives by reacting $S$-nucleophiles with reagent I (Scheme 6). The transformation proceeded

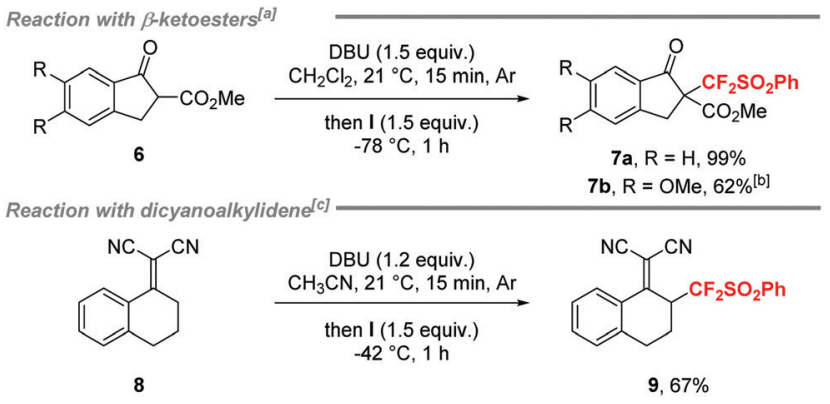

Scheme 5 Isolated yields are given. ${ }^{a}$ Reaction performed on a $0.1 \mathrm{mmol}$ scale. ${ }^{b}$ Reaction performed on a $0.15 \mathrm{mmol}$ scale for $30 \mathrm{~min}$ instead of $1 \mathrm{~h}$. ${ }^{c}$ Reaction performed on a $0.2 \mathrm{mmol}$ scale.

smoothly with structurally diverse thiophenol derivatives (10a-10c) including the 2-benzothiazolethiol 10c under mild reaction conditions $\left(50{ }^{\circ} \mathrm{C}\right.$, no base). Interestingly, in the case of the 4-mercaptophenol 10b, complete selectivity was observed for the formation of a $S-\mathrm{CF}_{2} \mathrm{SO}_{2} \mathrm{Ph}$ bond over a C(sp $\left.{ }^{2}\right)-\mathrm{CF}_{2} \mathrm{SO}_{2} \mathrm{Ph}$ bond.

To further showcase the synthetic utility of reagent $\mathbf{I}$, the straightforward synthesis of a $\mathrm{PhSO}_{2} \mathrm{CF}_{2}$-analog of Lidocaine 12, an anesthetic, was achieved in $63 \%$ overall yield after the following sequence: (phenylsulfonyl)difluoromethylation of the commercially available 2,6-xylidine (3k, $84 \%$ yield), followed by amidation with the chloroacetyl chloride and reaction with diethylamine under basic conditions in a one pot process $(75 \%$ yield, Scheme 7). Pleasingly, this fluorinated group was then converted into the valuable $\mathrm{HCF}_{2}$ moiety. ${ }^{5}$ Indeed, in the presence of $\mathrm{Mg}$ and using a catalytic amount of $\mathrm{I}_{2}$, the difluoromethylated product $\mathbf{1 3}$ was obtained in $80 \%$ yield starting from $\mathbf{1 2}$.

In summary, a straightforward synthesis of a bench-stable $\mathrm{PhSO}_{2} \mathrm{CF}_{2}$ reagent I was developed. This transition metal-free protocol was convenient and efficiently scalable and did not require any use of ozone depleting fluorinated reagents. Pleasingly, access to unprecedented fluorinated scaffolds was possible under simple and practical reaction conditions, as illustrated by the synthesis of $\mathrm{PhSO}_{2} \mathrm{CF}_{2}$-containing aniline derivatives and electron-rich (hetero)arenes in moderate to excellent yields. Moreover, reagent I was also applied to the functionalization of $\mathrm{C}\left(\mathrm{sp}^{3}\right)$ centers and for the preparation of valuable $\mathrm{PhSO}_{2} \mathrm{CF}_{2} \mathrm{~S}$-containing derivatives. The $\mathrm{PhSO}_{2} \mathrm{CF}_{2}$ residue was efficiently converted into the high-value added $\mathrm{HCF}_{2}$

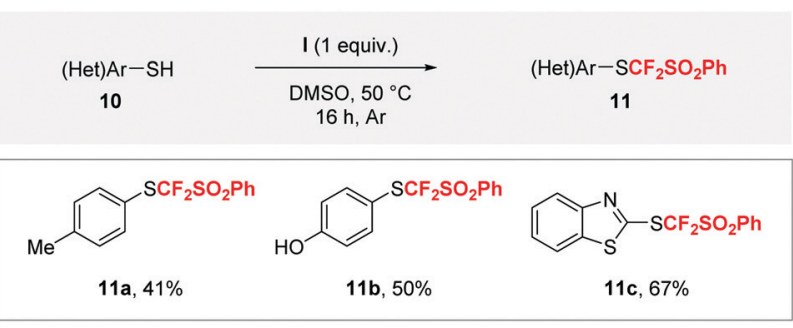

Scheme 6 Synthesis of (phenylsulfonyl)difluoromethylthio-containing molecules from thiol derivatives. Reaction conditions: 10 (3 equiv.), I (0.3 mmol, 1 equiv.), DMSO (0.15 M), $50{ }^{\circ} \mathrm{C}, 16 \mathrm{~h}$, under argon. Isolated yields are given. 


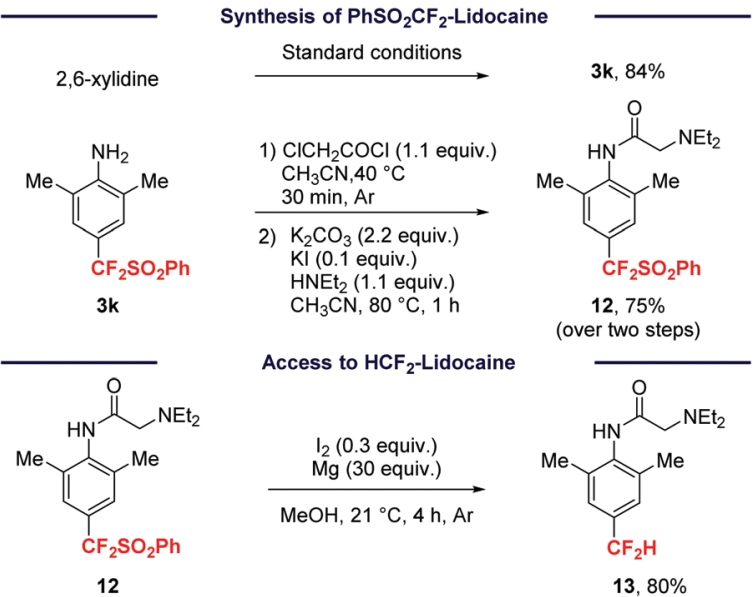

Scheme 7 Synthesis of $\mathrm{PhSO}_{2} \mathrm{CF}_{2}$-Lidocaine and the post-functionalization reaction.

group, which highlighted the versatility of this fluorinated group. The late-stage functionalization of bioactive molecules into their corresponding $\mathrm{PhSO}_{2} \mathrm{CF}_{2}$-containing analogs further demonstrated the synthetic utility of the novel reagent, which is particularly appealing in the quest for interesting scaffolds for medicinal chemistry. This newly-designed electrophilic source is distinguished by its straightforward and practical synthesis and its wide scope, thus offering a new platform to introduce the $\mathrm{PhSO}_{2} \mathrm{CF}_{2}$ motif into various skeletons. We believe that this original tool will enlarge the current toolbox of electrophilic reagents, will open new routes for functionalizing complex molecules and will be useful for the discovery of new bioactive molecules.

This work has been partially supported by the University of Rouen Normandy, INSA Rouen Normandy, the Centre National de la Recherche Scientifique (CNRS), the European Regional Development Fund (ERDF), Labex SynOrg (ANR-11-LABX-0029), the Carnot Institute I2C, the graduate school for research XL-Chem (ANR-18-EURE-0020 XL CHEM), and the Region Normandy. E. N. and T. B. thank the European Research Council (ERC) under the European Union's Horizon 2020 research and innovation programme (grant agreement no. 758710). E. N. thanks the Region Normandy for a doctoral fellowship.

\section{Conflicts of interest}

There are no conflicts to declare.

\section{Notes and references}

1 (a) J. Wang, M. Sánchez-Roselló, J. L. Aceña, C. del Pozo, A. E. Sorochinsky, S. Fustero, V. A. Soloshonok and H. Liu, Chem. Rev., 2014, 114, 2432; (b) S. Purser, P. R. Moore, S. Swallow and V. Gouverneur, Chem. Soc. Rev., 2008, 37, 320; (c) E. P. Gillis, K. J. Eastman, M. D. Hill, D. J. Donnelly and N. A. Meanwell, J. Med. Chem., 2015, 58, 8315; (d) E. A. Ilardi, E. Vitaku and J. T. Njardarson, J. Med. Chem., 2014, 57, 2832; (e) K. Müller, C. Faeh and F. Diederich, Science, 2007, 317, 1881.

2 M. Inoue, Y. Sumii and N. Shibata, ACS Omega, 2020, 5, 10633.

3 D. O'Hagan, Chem. Soc. Rev., 2008, 37, 308.

4 For a selection of reviews, see: (a) K. L. Kirk, Org. Process Res. Dev., 2008, 12, 305; (b) T. Liang, C. N. Neumann and T. Ritter,
Angew. Chem., Int. Ed., 2013, 52, 8214; (c) T. Besset, T. Poisson and X. Pannecoucke, Chem. - Eur. J., 2014, 20, 16830; (d) G. Landelle, A. Panossian and F. R. Leroux, Curr. Top. Med. Chem., 2014, 14, 941; (e) E. Merino and C. Nevado, Chem. Soc. Rev., 2014, 43, 6598; (f) H. Egami and M. Sodeoka, Angew. Chem., Int. Ed., 2014, 53, 8294; $(g)$ J. Charpentier, N. Früh and A. Togni, Chem. Rev., 2015, 115, 650; $(h)$ P. A. Champagne, J. Desroches, J.-D. Hamel, M. Vandamme and J.-F. Paquin, Chem. Rev., 2015, 115, 9073; (i) X. Liu, C. Xu, M. Wang and Q. Liu, Chem. Rev., 2015, 115, 683; (j) C. Ni and J. Hu, Chem. Soc. Rev., 2016, 45, 5441; (k) H.-X. Song, Q.-Y. Han, C.-L. Zhao and C.-P. Zhang, Green Chem., 2018, 20, 1662; (l) Y. Pan, ACS Med. Chem. Lett., 2019, 10, 1016; (m) L. Ruyet and T. Besset, Beilstein J. Org. Chem., 2020, 16, 1051; (n) F. Tian, G. Yan and J. Yu, Chem. Commun., 2019, 55, 13486.

5 (a) J. A. Erickson and J. I. McLoughlin, J. Org. Chem., 1995, 60, 1626; (b) M. D. Martínez, L. Luna, A. Y. Tesio, G. E. Feresin, F. J. Durán and G. J. Burton, J. Pharm. Pharmacol., 2016, 68, 233; (c) N. A. Meanwell, J. Med. Chem., 2011, 54, 2529; (d) C. D. Sessler, M. Rahm, S. Becker, J. M. Goldberg, F. Wang and S. J. Lippard, J. Am. Chem. Soc., 2017, 139, 9325; (e) Y. Zafrani, D. Yeffet, G. Sod-Moriah, A. Berliner, D. Amir, D. Marciano, E. Gershonov and S. Saphier, J. Med. Chem., 2017, 60, 797; $(f)$ Y. Zafrani, G. Sod-Moriah, D. Yeffet, A. Berliner, D. Amir, D. Marciano, S. Elias, S. Katalan, N. Ashkenazi, M. Madmon, E. Gershonov and S. Saphier, J. Med. Chem., 2019, 62, 5628.

6 For a selection of reviews, see: $(a)$ G. K. S. Prakash and J. Hu, Acc. Chem. Res., 2007, 40, 921; (b) J. Hu, J. Fluorine Chem., 2009, 130, 1130; (c) J. Hu, W. Zhang and F. Wang, Chem. Commun., 2009, 7465; (d) G. Landelle, A. Panossian, S. Pazenok, J.-P. Vors and F. R. Leroux, Beilstein J. Org. Chem., 2013, 9, 2476; (e) J. B. I. Sap, C. F. Meyer, N. J. W. Straathof, N. Iwumene, C. W. Am Ende, A. A. Trabanco and V. Gouverneur, Chem. Soc. Rev., 2021, 50, 8214; (f) R. Jia, X. Wang and J. Hu, Tetrahedron Lett., 2021, 75, 153182; for selected examples, see: $(g)$ Y.-M. Su, Y. Hou, F. Yin, Y.-M. Xu, Y. Li, X. Zheng and X.-S. Wang, Org. Lett., 2014, 16, 2958; $(h)$ G. Yin, M. Zhu and W. Fu, Heterocycl. Commun., 2017, 23, 275; (i) N. Surapanich, C. Kuhakarn, M. Pohmakotr and V. Reutrakul, Eur. J. Org. Chem., 2012, 5943.

7 H. Eto, Y. Kaneko, S. Takeda, M. Tokizawa, S. Sato, K. Yoshida, S. Namiki, M. Ogawa, K. Maebashi, K. Ishida, M. Matsumoto and T. S. Asaoka, Chem. Pharm. Bull., 2001, 49, 173.

8 (a) J. Pepin, C. Guern, F. Milord and P. J. Schechter, Lancet, 1987, 330, 1431; (b) J. E. Wolf Jr, D. Shander, F. Huber, J. Jackson, C.-S. Lin, B. M. Mathes and K. Schrode, the Eflornithine HCl Study Group, Int. J. Dermatol., 2007, 46, 94.

9 B. Bennett, A. Matagne, P. Michel, M. Leonard, M. Cornet, M.-A. Meeus and N. Toublanc, Neurotherapeutics, 2007, 4, 117.

10 (a) W. Zhang, J. Zhu and J. Hu, Tetrahedron Lett., 2008, 49, 5006; (b) Z. He, T. Luo, M. Hu, Y. Cao and J. Hu, Angew. Chem., Int. Ed., 2012, 51, 3944; (c) Z. He, M. Hu, T. Luo, L. Li and J. Hu, Angew. Chem., Int. Ed., 2012, 51, 11545.

11 X. Wang, G. Liu, X.-H. Xu, N. Shibata, E. Tokunaga and N. Shibata, Angew. Chem., Int. Ed., 2014, 53, 1827.

12 (a) C. Zhang, Org. Biomol. Chem., 2014, 12, 6580 and references therein: (b) G. K. S. Prakash, C. Weber, S. Chacko and G. A. Olah, Org. Lett., 2007, 9, 1863.

13 P. Franzmann, S. B. Beil, D. Schollmeyer and S. R. Waldvogel, Note that disulfide 1a was easily prepared from 2-phenylaniline after a four-step synthesis (no purification) with several grams (upto $50 \mathrm{~g}$ ) by following the procedure depicted, Chem. - Eur. J., 2019, 25, 1936.

$14 \mathrm{PhSO}_{2} \mathrm{CF}_{2} \mathrm{H}$ was prepared in two steps from thiophenol when not purchased, see the ESI $\dagger$.

15 For more details, see the ESI $\dagger$.

16 For a similar selectivity in the case of trifluoromethylation with the Umemoto reagent, see: (a) T. Umemoto and S. Ishihara, Tetrahedron Lett., 1990, 31, 3579; (b) T. Umemoto, S. Ishihara and K. Adachi, J. Fluorine Chem., 1995, 74, 77; (c) Y. Macé, B. Raymondeau, C. Pradet, J.-C. Blazejewski and E. Magnier, Eur. J. Org. Chem., 2009, 1390.

17 (a) H.-Y. Xiong, X. Pannecoucke and T. Besset, Chem. - Eur. J., 2016, 22, 16734; (b) X. Xiao, Z.-T. Zheng, T. Li, J.-L. Zheng, T. Tao, L.-M. Chen, J.-Y. Gu, X. Yao, J.-H. Lin and J.-C. Xiao, Synthesis, 2020, 197; (c) T. Besset and T. Poisson, in Emerging Fluorinated Motifs: Synthesis, Properties and Applications, ed. D. Cahard and J.-A. Ma, Wiley-VCH, Weinheim, 2020, 16, 449-475; (d) E. Ismalaj, D. Le Bars and T. Billard, Angew. Chem., Int. Ed., 2016, 55, 4790. 